\title{
A Behavioral Finance Study: Effect of Personal Characteristics on Risk Preferences and Investment Decisions of Vietnamese Investors
}

\author{
Tang Thi Thanh THUY ${ }^{*}$, Vo Thi Nhu NGOC ${ }^{2}$ \\ 1,2 Faculty of Business Administration, Foreign Trade University, Hanoi, Vietnam \\ ${ }^{*}$ Corresponding author: thuyttt@ftu.edu.vn
}

\begin{abstract}
Vietnam's financial investing market, especially the stock market, overcame the "Year of Covid-19" spectacularly with an exceptionally strong recovery, record-high liquidity, and the enthusiastic participation of new investors, surpassing all expectations. Now that the markets are expanding fast, individual investors and financial advisors need to upgrade their understanding of the investing markets, and be ready to adapt to the vast wave of newcomers. It is, therefore, necessary to explore behavioral factors including emotions and cognition that play a significant role in explaining investors decision making process, so as to help the investors as well as financial advisors make better predictions and decisions for their business.
\end{abstract}

\section{Research purpose:}

This research explores the behavioral characteristics influencing risk preferences and investment decisions of Vietnamese individual investors. The combination of The Big Five Personality Model and Cognitive Reflection Test constructs an investor characteristic profile, which hinders a correlation with investors' risk aversion and investment decision-making.

\section{Research motivation:}

The motivation for this research stems largely from the need of knowing the many diverse factors that might influence risk behavior, as well as the need to better understand how behavioral traits might influence risk choices connected to investing. It contributes to not only behavioral finance theory but also general economic analysis and professional practices.

\section{Research design, approach, and method:}

The study utilizes a sample of 321 investors and potential investors on the Big Five personality scales and the Cognitive Reflection Test. The scales for the financial dimensions are based on concepts developed from extant literature. The collected data are analyzed using SPSS with tests include Cronbach's Alpha, Exploratory Factor Analysis, regression, and one-way ANOVA with post hoc test in Bonferroni correction.

\section{Main findings:}

Neuroticism, extraversion, and conscientiousness were found to have a significant direct influence on risk aversion; while agreeableness and openness to experience have an inverse relationship with risk aversion. Performance in the Cognitive Reflection Test does provide evidence on risk preferences, the relationship of which is non-linear. Risk aversion negatively affects investment decision.

\section{Practical/managerial implications:}

Awareness of the influence of specific personality traits in financial decision making would help financial planners tailor products more effectively to cater for the understanding and lifestyle of investors. Several recommendations regarding the discovered relationships are put forward to further assist individual investors as well as investment advisors in professional practice.

Keywords: Behavioral finance, Personal characteristics, Big Five personality traits, Cognitive Reflection Test, Risk preferences, Investment decision

\section{INTRODUCTION}

Vietnam's financial investing market, especially the stock market, overcame the "Year of Covid-19" spectacularly with an exceptionally strong recovery, record-high liquidity, and the enthusiastic participation of new investors, surpassing all expectations. With the markets expanding fast, individual investors and financial advisors need to upgrade their understanding of the investing markets, and be ready to adapt to the 
vast wave of newcomers. It is, therefore, necessary to explore behavioral factors including emotions and cognition that play a significant role in explaining investors' decision making process, so as to help the investors as well as financial advisors raise better predictions and decisions for their business.

\section{LITERATURE REVIEW AND HYPOTHESIS DEVELOPMENT}

\subsection{Behavioral finance}

The Expected Utility Theory (EUT) is the normative model of rational choice and descriptive model of economic behavior, which dominates the analysis of decision making under risk, also known as standard finance. The foundation of standard finance is also associated with the Modern Portfolio Theory and Efficient Market Hypothesis (Ricciardi and Simon, 2001). These traditional theories were well-crafted in order to make sound financial judgments. They were, however, unable to explain market disruptions, which manifested themselves from time to time in the form of market bubbles, market overreaction or underreaction, momentum and reversals. The EUT was challenged by Kahneman and Tversky, who demonstrated a pattern of behavior in which errors are systematic, non-random, and the EUT is insufficient in the majority of economic behavior models. In this context, behavioral finance began to emerge, with the goal of providing behavioral explanations for such abnormalities.

Prospect theory is regarded as the opposing approach of EUT to decision-making from different perspectives. Prospect theory focuses on subjective decision-making under the influence of the investors' value system, whereas EUT concentrates on investors' rational expectations (Filbeck, Hatfield and Horvath, 2005). A key feature of this idea is that rather of judging absolute magnitudes, people assess changes or differences to their position relative to a reference point. According to prospect theory, individuals are risk averse when it comes to gains and risk seeking when it comes to losses. This signifies that the value function is S-shaped, concave above and convex below the reference point (Kahneman and Tversky, 1979). The literature of prospect theory for analysis of decision-making under risk establishes the seminal work in behavioral finance and formed the bedrock of such field. Ricciardi and Simon (2001) has defined behavioral finance as the science of utilizing insights from other sciences and business disciplines to explain the choices made by investors. Alternatively, Pompian (2016, p. 2) puts it:

"Behavioral finance attempts to understand and explain actual investor behavior, in contrast to theorizing about investor behavior. It differs from traditional (or standard) finance, which is based on assumptions of how investors and markets should behave".

\subsection{Personal characteristics}

Behavioral finance considers qualitative elements where risk may be seen in both personality and cognition (Olsen, 2007, 2008). Theoretical framework highlights the interplay between emotions and cognition in decision-making by taking a "two-system" approach, which is a potential mechanism for understanding the link from personality and cognition to risk preferences (Thaler and Shefrin, 1981).

Personality is described as "that pattern of characteristic thoughts, feelings, and behaviors that distinguishes one person from others and that persists over time and situation" (Phares, 1988). Durand et al. (2008) indicated that personality is a "motivator" of human behavior. To measure personality, in 1987, McCrae \& Costa proposed five major domains as the Big Five personality traits, whose key characteristics and measurement are summarized in table 1.

Table 1: Five dimensions of measuring personality traits

\section{High Scorer} Characteristics

Worrying, nervous,
emotional, insecure.

(E) Extraversion

O) Openness to experience

(A) Agreeableness
Sociable, active, talkative, person -oriented, fun-loving, optimistic.

Curious, broad interests, creative, original.

Soft-hearted, good-natured,
Factor Measures...

Low Scorer Characteristics

Calm, relaxed, unemotional, hearty, self-satisfied

Reserved, sober, non-exuberant, aloof, task-oriented, quiet. and capacity for joy.

amount of proactive-seeking, and appreciation of experience for its own sake, toleration for and exploration of the unfamiliar.

the quality of interpersonal orientation along a continuum for compassion to antagonism in
Conventional, down-to-earth, narrow interests, unartistic, unanalytical. Cynical, rude, suspicious, 
trusting, helpful, thoughts, feelings and actions.

gullible,

straightforward.

(C) Organized, reliable,

Conscientious-ness hard-working, punctual, neat, and persevering. the degree of organization persistence, and motivation and goal-directed behavior. Contrasts dependable, fastidious people with those who are lackadaisical. uncooperative, ruthless, irritable, and manipulative. Aimless, unreliable, lazy, careless, negligent, weak-willed.

(Source: McCrae \& Costa, 1987)

Cognitive ability may influence investment decisions via at least three distinct ways: (i) maintaining a portfolio requires a particular human capital investment in terms of the time and effort required to get acquainted with the concepts of transaction costs, asset returns, volatility, and covariance between asset returns (Christelis, Jappelli and Padula, 2010); (ii) the possible relationship between cognitive capacity and the curvature of the value function is a second conduit between financial decisions and asset holding; and (iii) inadequate cognitive skills are related with a reduced capacity to process information, and that memory influences the capability to comprehend conditional probabilities and discern between relevant and irrelevant information (Spaniol and Bayen, 2005). Individuals with low cognitive skills tend to be risk-averse (and more risk-averse than those with high cognitive ability) when investing in low risk asset classes, but risk-seeking (though less risk-seeking than those with high cognitive ability) when investing in high risk asset classes, according to experimental studies (Park, 2016; Dohmen et al., 2018). Thus, this research seeks to present a broad picture of cognitive ability and risk preferences building on prior relevant investigations.

Frederick introduced the Cognitive Reflection Test (CRT) in his study in 2005, and it seeks to assess people's cognitive ability. It is intended to test the ability to replace an impulsive, wrong answer with reflection that leads to the right one (Frederick, 2005). DeYoung approved the use of the CRT in collaboration with the Big Five (DeYoung, Grazioplene and Peterson, 2012). Frederick's three-item CRT is provided below.

(CRT1) A bat and a ball cost $\$ 1.10$ in total. The bat costs $\$ 1.00$ more than the ball. How much does the ball cost? cents

(CRT2) If it takes 5 machines 5 minutes to make 5 widgets, how long would it take 100 machines to make 100 widgets? minutes
(CRT3) In a lake, there is a patch of lily pads. Everyday, the patch doubles in size. If it takes 48 days for the patch to cover the entire lake, how long would it take for the patch to cover half of the lake? days

\subsection{Investor risk profile and investment decision}

Each person has a risk profile that governs their behavior when it comes to investing in uncertain situations. Risk preference, also known as risk appetite, is the amount of risk that a person is prepared to accept in exchange for a payoff (Pompian, 2016). A person with a high degree of risk aversion will constantly want to avoid risk in his investing choices, whether he has to bear a loss for it, and will never be ready to invest in any hazardous assets. It has also been shown that risk aversion and materialism modify the association between financial numeracy and financial decision outcomes (Huhmann and McQuitty, 2009).

Financial planning is the process of reaching one's financial objectives in life via effective financial management (Nga and Ken Yien, 2013). Personal financial investment may be divided into two categories: long-term financial investment and short-term financial investment (Russia \& Yien, 2013). The long-term financial investment intentions of individuals involve products with long maturities to meet long-term financial needs. While the short-term financial investments of individuals are related to meeting financial needs in the near future.

\section{METHODOLOGY}

\subsection{Research hypotheses}

As personal characteristics can explain the formation of individual intentions to invest in the financial market, this study proposes that personal characteristics, such as personality traits and cognitive reflection, affect risk aversion towards financial investment, which in turn influences individuals' investment intentions. Therefore, the following hypotheses are proposed: 


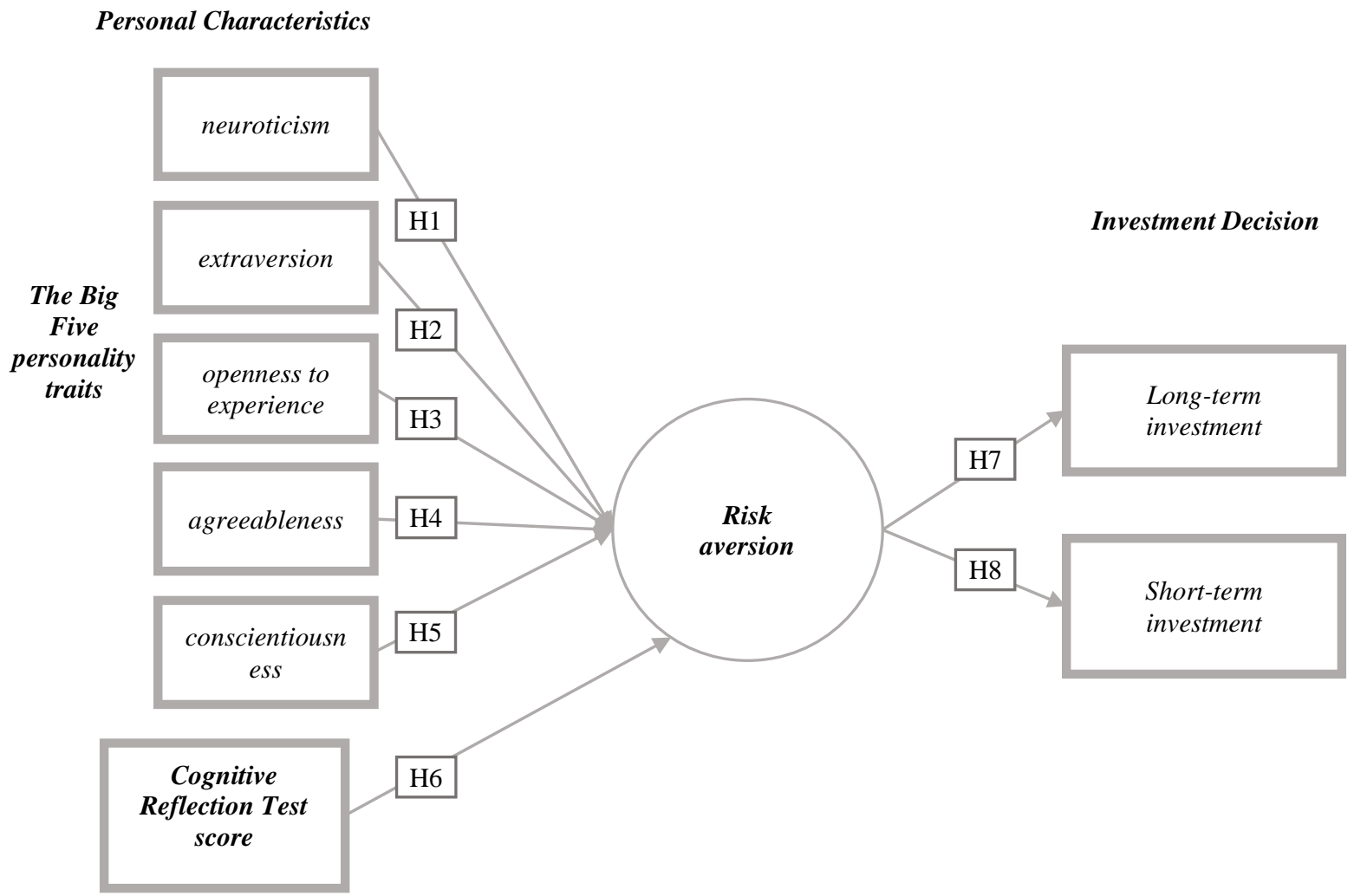

Fig. 1: Research model

(Souce: Author, 2021)

H1 - Neuroticism exerts a significant positive influence on risk aversion.

$\mathrm{H} 2$ - Extraversion exerts a significant negative influence on risk aversion.

H3 - Openness to experience exerts a significant negative influence on risk aversion.

H4 - Agreeableness exerts a significant positive influence on risk aversion.

H5 - Conscientiousness exerts a significant positive influence on risk aversion.

H6 - An individual's score on the Cognitive Reflection Test provides significant evidence on risk aversion.

H7 - Risk aversion exerts an inverse effect on short-term investment.

H8 - Risk aversion exerts an inverse effect on long-term investment.

Fig. 1 maps the research model of this study formed by the above eight hypotheses

\subsection{Design of questionnaire \& data collection}

The questionnaire used for this study was designed in accordance with in-depth interviews with five Vietnamese investors with more than five years of investment experience and the testing with a sample of 50 respondents. The six-point Likert scale, a rating system frequently used for questioning respondents' opinions and attitudes (Fisher, 2010), is used to ask individual investors to assess their level of agreement with regard to behavioral characteristics, risk aversion, and investment goals. The structured online questionnaire collected data for this study. Inquiries to the questionnaire were posted on social media and on groups of financial investors as well as undergraduates and working adults. All questionnaires were completed voluntarily by respondents. 321 respondents met with relevant requirements under the model and their provided data were used for the research.

\subsection{Applied statistical model \& data analysis}

To begin with, descriptive statistics is generated. Reliability are next examined using Cronbach's Alpha for theoretical concept (Saunders, Lewis and Thornhill, 2019) and corrected item-total correlation (F. Hair Jr et al., 2014). Since this is considered a new study, Cronbach's Alpha coefficient should be at least 0.6, and corrected item-total correlation at least 0.3 (F. Hair Jr et al., 2014). Because of the uncertainty about the connection between components, Exploratory Factor Analysis (EFA) was employed to analyze the underlying behavioral determinants from the answers. The appropriate standards to use EFA include Kaiser-Meyer-Olkin (KMO) measure of sampling adequacy coefficient at least 0.5 , p-value of Bartlett's test lower than 0.05, Eigenvalue greater than 1, total variance explained (cumulative percentage of rotation sums of squared loadings) at least $50 \%$, and factor 
loading coefficient higher than 0.5 (F. Hair Jr et al., 2014). After EFA, linear regression was analyzed for Neuroticism, Extraversion, Openness to experience, Agreeableness, Conscientiousness, and risk aversion. Linear regression was also used to analyze the relationship between risk aversion and investment decisions. All relationships with $\mathrm{p}$-value $>0.05$ are statistically significant, with each's level of effect determined by Beta. Due to the CRT score variable consisting of numbers of correct answers $(0,1,2$, or 3$)$, one-way ANOVA with post hoc test (Bonferroni) was used to assess the evidence CRT scores provide on risk aversion. The model is eligible for ANOVA analysis when there is no difference in the variance between groups, which requires the p-value on Test of Homogeneity of Variances to be larger than 0.05 .

\section{RESULTS AND DISCUSSION}

\subsection{Description of respondents \& study variables}

321 questionnaire respondents' descriptive data is presented in table 2 .

Table 2: Descriptive statistics of respondents

\begin{tabular}{|c|c|c|}
\hline & Frequency & Percent \\
\hline \multicolumn{3}{|l|}{ Gender } \\
\hline Male & 213 & 66.4 \\
\hline Female & 108 & 33.6 \\
\hline \multicolumn{3}{|l|}{ Age } \\
\hline 18-25 years & 143 & 44.5 \\
\hline $26-35$ years & 86 & 26.8 \\
\hline $35-50$ years & 71 & 22.1 \\
\hline Above 50 years & 21 & 6.5 \\
\hline \multicolumn{3}{|l|}{ Academic level } \\
\hline Undergraduate & 107 & 33.3 \\
\hline Bachelor in Economics-related majors & 94 & 29.3 \\
\hline Bachelor in other majors & 84 & 26.2 \\
\hline Master & 30 & 9.3 \\
\hline Doctor & 6 & 1.9 \\
\hline \multicolumn{3}{|l|}{ Monthly income } \\
\hline Under 4 million VND & 68 & 21.2 \\
\hline From 4 million to under 9 million VND & 90 & 28.0 \\
\hline From 9 million to under 15 million VND & 102 & 31.8 \\
\hline From 15 million to under 25 million VND & 37 & 11.5 \\
\hline Above 25 million VND & 24 & 7.5 \\
\hline \multicolumn{3}{|l|}{ Knowledge on financial investing } \\
\hline Having no prior knowledge on financial investing & 23 & 7.2 \\
\hline Having some knowledge on financial investing but not yet intention to invest & 45 & 14.0 \\
\hline Having knowledge on financial investing and intention to invest & 113 & 35.2 \\
\hline Having only bank savings as financial investment & 53 & 16.5 \\
\hline Having participated in financial investing practice other than bank deposits & 87 & 27.1 \\
\hline Total & 321 & 100.0 \\
\hline
\end{tabular}

(Souce: Author, 2021)

The profile of the survey participants above shows that the sample was diverse in terms of demographics, academic level, income, as well as financial investing knowledge and intention.

Table 3 summarizes the variables involved in qualitative analysis and their input data coding for SPSS software.

Table 3: Description of study variables

\begin{tabular}{llcl} 
Factor name \& sign & Observed variables & Range & \multicolumn{1}{c}{ Description } \\
\hline Neuroticism (NEU) & NEU1, NEU2 & $1-6$ & $\begin{array}{l}\text { High scores indicate tenseness, moodiness, anxiety, and } \\
\text { insecurity }\end{array}$ \\
Extraversion (EXT) & $\begin{array}{l}\text { EXT1, EXT2, } \\
\text { EXT3 }\end{array}$ & $1-6$ & $\begin{array}{l}\text { High scores indicate assertiveness, sociability, talkativeness, } \\
\text { optimism, and being upbeat and energetic }\end{array}$ \\
Oppenness to & $\begin{array}{l}\text { OPE1, OPE2, } \\
\text { OPperience (OPE) }\end{array}$ & $1-6$ & $\begin{array}{l}\text { High scores indicate an active imagination, aesthetic } \\
\text { sensitivity, a preference for variety, intellectual curiosity, and } \\
\text { broad cultural interest }\end{array}$
\end{tabular}




\begin{tabular}{|c|c|c|c|}
\hline $\begin{array}{l}\text { Agreeableness } \\
(\text { AGR) }\end{array}$ & AGR1, AGR2 & $1-6$ & $\begin{array}{l}\text { High scores indicate altruism, personal warmth, sympathy } \\
\text { towards others, helpfulness, and cooperation }\end{array}$ \\
\hline $\begin{array}{l}\text { Conscientiousness } \\
(\mathrm{CST})\end{array}$ & $\begin{array}{l}\text { CST1, CST2, } \\
\text { CST3 }\end{array}$ & $1-6$ & $\begin{array}{l}\text { High scores indicate purposefulness, being strong-willed, } \\
\text { determination, organization, reliability, and punctuality }\end{array}$ \\
\hline CRT score (CRT) & CRT & $1-4$ & $\begin{array}{l}\text { The number of correct answers in the CRT }(1,2,3,4 \\
\text { indicate } 0,1,2,3 \text { correct answers, respectively) }\end{array}$ \\
\hline $\begin{array}{l}\text { Risk aversion } \\
\text { (RAV) }\end{array}$ & $\begin{array}{l}\text { RAV1, RAV2, } \\
\text { RAV3, RAV4 }\end{array}$ & $1-6$ & $\begin{array}{l}\text { High scores indicate high risk aversion/avoidance and low } \\
\text { risk-seeking attitude towards financial investing }\end{array}$ \\
\hline $\begin{array}{l}\text { Short-term } \\
\text { investments (STI) }\end{array}$ & $\begin{array}{l}\text { STI1, STI2, STI3, } \\
\text { STI4, STI5 }\end{array}$ & $1-6$ & $\begin{array}{l}\text { High scores indicate high likelihood to invest over } \\
\text { short-term intentions }\end{array}$ \\
\hline $\begin{array}{l}\text { Long-term } \\
\text { investments (LTI) }\end{array}$ & $\begin{array}{l}\text { LTI1, LTI2, LTI3, } \\
\text { LTI4, LTI5 }\end{array}$ & $1-6$ & $\begin{array}{l}\text { High scores indicate high likelihood to invest over long-term } \\
\text { intentions }\end{array}$ \\
\hline \multicolumn{3}{|c|}{ NEU = Mean (NEU1, NEU2) } & $\mathrm{CST}=$ Mean $(\mathrm{CST} 1, \mathrm{CST} 2, \mathrm{CST} 3)$ \\
\hline \multicolumn{3}{|c|}{$\mathrm{EXT}=$ Mean $(\mathrm{EXT} 1, \mathrm{EXT} 2, \mathrm{EXT} 3)$} & RAV $=$ Mean (RAV1, RAV2, RAV3, RAV4) \\
\hline \multicolumn{3}{|c|}{ OPE = Mean (OPE1, OPE2, OPE3) } & $\mathrm{STI}=$ Mean $(\mathrm{STI} 1, \mathrm{STI} 2, \mathrm{STI} 3, \mathrm{STI} 4, \mathrm{STI} 5)$ \\
\hline \multicolumn{3}{|c|}{ AGR = Mean (AGR1, AGR2) } & LTI = Mean (LTI1, LTI2, LTI3, LTI4, LTI5) \\
\hline
\end{tabular}

(Souce: Author, 2021)

NEU, EXT, OPE, AGR, CST, and CRT make up the fundamental level of the research model, which are examined for influence on RAV - the middle level. RAV is tested for impact on STI and LTI, which is the last level of the model.

\subsection{Data analysis \& interpretation}

\subsubsection{Effects of the Big Five traits on risk aversion}

In order to evaluate the effects of the Big Five personality traits on risk aversion, linear regression was used with five independent variables (NEU, EXT, OPE, AGR, CST) and one dependent variable (RAV). The model summary shows $\mathrm{R}$ Square $=0.659$ and adjusted $\mathrm{R}$ Square $=0.654$, which reveals that $65.4 \%$ of the data fit the regression model. The p-value of the F-test is 0.000 $<0.05$. Thus, the constructed linear regression model is suitable for the population.

The results show that in the regression model, p-value coefficients of the independent variables are all less than 0.05 , so all relationships are statistically significant. The results observed indicate three factors with direct relationships - NEU, EXT, CST, and two factors with inverse relationships - OPE, AGR, with RAV. Hypotheses H1, H3, H5 are supported, while $\mathrm{H} 2$ and $\mathrm{H} 4$ are rejected. In ascending level of effect order, NEU, CST, and EXT have a direct relationship with RAV with Beta of $0.275,0.422$, and 0.502 , respectively; while AGR, and OPE have an inverse relationship with RAV with Beta of -0.327 , and -0.507 .

\subsubsection{Effects of the score of the Cognitive Reflection Test on risk aversion}

In order to evaluate the effects of the CRT score on risk aversion, one-way ANOVA was used to determine whether there are any statistically significant differences between the means of four groups: No correct answer, 1 correct answer, 2 correct answers, and 3 correct answers.

Only roughly one thirds of the respondents answered all three questions correctly, which is the highest proportion among four outcomes. The other three shared the remaining two thirds relatively evenly, with each occupying over $20 \%$ of total respondents. The minor group must be those who had no correct answer, making up $21 \%$ of total sample data. This information is illustrated in Fig. 2.

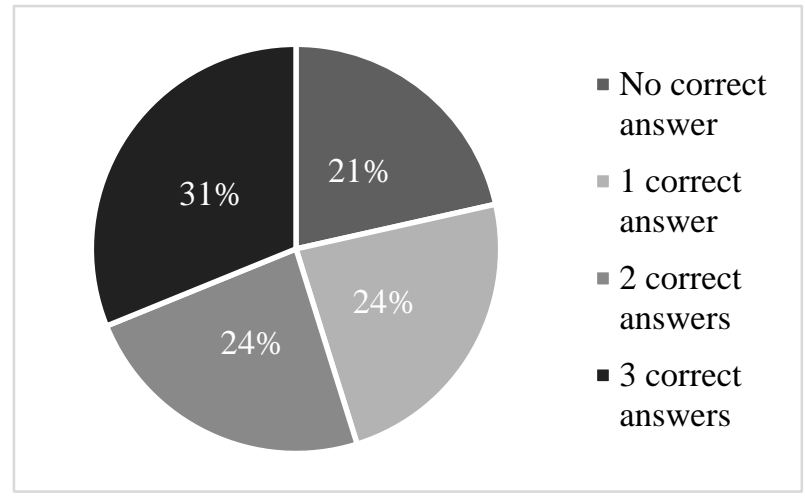

Fig. 2: CRT score pie chart

(Souce: Author, 2021)

ANOVA results present p-value $=0.000<0.05$, showing that there is a difference in RAV between CRT scores. Hypothesis H6 is therefore accepted. In order to identify which group is different from which and how different, post hoc test in Bonferroni correction is applied.

It can be noticed from the results of the post hoc test's multiple comparisons that except for two pairs $-1 \& 2$ correct answers, $0 \& 3$ correct answers - the differences in RAV of all four groups are significant since their p-value are $0.000<0.05$. These mean differences are demonstrated in Fig. 3. Overall, the relationship between CRT score and risk aversion is not linear, where those with no or all correct answers tend to be less risk averse than those getting 1 or 2 right. 


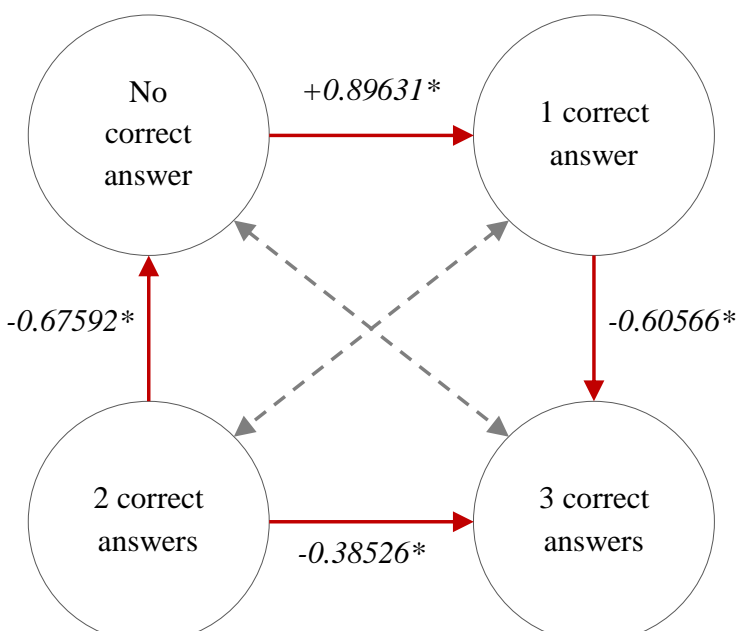

Fig. 3: Mean differences between CRT score groups

(Souce: Author, 2021)

\subsubsection{Effects of risk aversion on short-term and long-term investments}

In order to evaluate the effects of risk aversion on investing decisions, linear regression was used with $\mathrm{RAV}$ as the independent variable and two dependent variables (STI, LTI). The regression results show that in both regression model, p-value coefficients of RAV are less than 0.05 , so both relationships are statistically significant. As can be seen, Beta STI $=-0.721$ and Beta LTI $=-0.695$, RAV exerts an inverse relationship with both dependent variables. This also means that the proposed hypotheses $\mathrm{H} 7$ and $\mathrm{H} 8$ in this research's model are accepted.

\subsection{Discussion of the results}

The data analysis and interpretation presented above in section 4.2 has accepted several hypotheses and rejected the others. Table 4 summarizes the hypotheses, relationships tested, their Betas, significance level, and final verdict. Overall, only two hypotheses were rejected $(\mathrm{H} 2$ and $\mathrm{H} 4)$. Further analysis and possible explanations for the results will be discussed in this section.

Table 4: Summary of hypothesis testing

\begin{tabular}{lcccc}
\multicolumn{1}{c}{ Hypothesis } & Relationship & Beta & Sig. & Results \\
\hline $\begin{array}{l}\text { H1 - Neuroticism exerts a significant positive influence on risk } \\
\text { aversion. }\end{array}$ & NEU - RAV & 0.275 & 0.000 & Support \\
$\begin{array}{l}\text { H2 - Extraversion exerts a significant negative influence on } \\
\text { risk aversion. }\end{array}$ & EXT - RAV & 0.502 & 0.000 & Reject \\
$\begin{array}{l}\text { H3 - Openness to experience exerts a significant negative } \\
\text { influence on risk aversion. }\end{array}$ & OPE - RAV & -0.507 & 0.000 & Support \\
$\begin{array}{l}\text { H4 - Agreeableness exerts a significant positive influence on } \\
\text { risk aversion. }\end{array}$ & AGR - RAV & -0.327 & 0.000 & Reject \\
$\begin{array}{l}\text { H5 - Conscientiousness exerts a significant positive influence } \\
\text { on risk aversion. }\end{array}$ & CST - RAV & 0.422 & 0.000 & Support \\
$\begin{array}{l}\text { H6 - An individual's score on the Cognitive Reflection Test } \\
\text { provides significant evidence on risk aversion. }\end{array}$ & CRT - RAV & N/A & 0.000 & Support \\
$\begin{array}{l}\text { H7 - Risk aversion exerts an inverse effect on short-term } \\
\text { investment. }\end{array}$ & RAV - STI & -0.721 & 0.000 & Support \\
$\begin{array}{l}\text { H8 - Risk aversion exerts an inverse effect on long-term } \\
\text { investment. }\end{array}$ & RAV - LTI & -0.695 & 0.000 & Support
\end{tabular}

(Souce: Author, 2021)

Traits having a direct relationship with risk aversion are extraversion, conscientiousness, and neuroticism, ordered by level of effect from highest to lowest. Extraversion bears the strongest direct relationship with risk aversion. Extroverts are sociable, active, have a happy perspective on life, and is constantly looking forward to the future, which can explain their tendency to avoid risks, as they would not like add losses, worries and negativity in general to their lives. The relationship conscientiousness has with risk aversion is also a direct one with the dimension's effect being second strongest. This points in the same direction suggested by Nga and Ken Yien (2013), that risk aversion is directly influenced by the dimension. However, it contrasts with the findings of Tran et al. (2020). Individuals with a high level of conscientiousness are extremely cautious, responsible, and believe in being prepared, therefore the tendency to be alert to risks. Neuroticism is shown to affect an individual's attitude toward investment significantly and negatively. Those who always feel inferior to others, anxious, and insecure tend to ascertain that financial investments, especially stocks, are harmful and that people will lose money in trading. Neuroticism exerts a significant positive influence on risk aversion, which is consistent with most studies on behavioral finance, such as those by Durand et al. (2008), Nguyen (2020), and Tran et al. (2020).

At the same time, agreeableness and openness to experience have an inverse relationship with risk aversion, with more weight on the trait of openness. Openness to experience has a strong negative impact on risk aversion. Durand et al. (2008) discovered that those 
who are more open to experience have higher portfolio risk. Similar results were observed by Bortoli (2019), where more openness to experience equals greater risk propensity, Nandan et al. (2016) and Tran et al. (2020). The last dimension, agreeableness, inversely influences risk aversion. The more agreeable an individual is, the less risk he will try to avoid. This outcome is in line with previous studies by Tran et al. (2020) and contrasts with that of Nguyen (2020).

An individual's score on the CRT provides significant evidence on risk aversion. Individuals with highest cognitive reflection tended not to avoid risk in investment decisions, but were not daring either: they have a rather moderate profile. Those on the no-correct-answer side of the CRT scale were the most non-risk-averse. With such low tendency to detect errors and resist reporting the response that first comes to mind, maybe they are not fully aware of the risk that investing poses on their financial position. Those with one or two answers correct are the most risk averse: they recognize the risks they have to bear for profit, but do not reckon what those really are and how much damage can happen. This result is in line with descriptions by Dohmen et al. (2010), Bortoli (2019) and Rzeszutek et al. (2015), who pointed out that the relationship between these two variables - cognitive capacity and risk aversion - is non-linear.

Both short-term and long-term investment intentions of individuals are inversely influenced by the attitude towards financial risk of individuals. In other words, the more risk aversion an investor is, the less likely he or she is to choose either short-term or long-term investments. This result is consistent with that of Tran et al. (2020), which also found the negative relationship between risk aversion and investment decisions.

\subsection{Recommendations regarding research results}

In this research, personality traits, cognitive reflection, and risk behavior were all shown to have a role in investing decision. The study's findings have ramifications for individual investors, financial advisors, and financial organizations.

The findings of the present study would be useful for individual investors to identify their risk perception behavior and consequently assisting their investment decision-making. This research contributes to this body of knowledge by arguing that, in limited rationality circumstances, being conscious of an individual's personal characteristics would help one understand and assess his or her own financial judgments, allowing one to make better decisions.

This research study places a high value on the financial investing advisory industry, including investment advisers, and investment marketers. The results of this research study may be utilized to advise customers who invest in mutual funds or in investment marketers to do a personality characteristic analysis before making their investments. Understanding the link between personality traits, cognitive reflection, risk preferences, and decision-making will assist financial planners in tailoring products and services to better suit the needs of their potential clients. As a consequence of the findings of this research, financial service providers may get insight into individuals' financial risk attitudes and, as a result, their investment intentions. When providing advise to clients, financial managers and investment advisors should examine their personality characteristics and financial risk behavior, among other things. Suggestions of the right avenues of investment or suitable portfolio at the right times in such a way that enhances clients' investing experience must be made accordingly. When practiced with dedication, behavioral finance offers the ability to develop a strong bond between client and advisor and to take a comprehensive grasp of client's motives and fears, enabling advisor to convince client of a suitable portfolio, why it is designed the way it is, and why it is the right portfolio for him or her - regardless of what happens from day to day in the markets.

Financial organizations may also create marketing tactics based on the characteristics of its prospects. Individuals do not always make investment choices based on logical criteria; rather, their judgments are influenced by certain other factors that are influenced by characteristics. Consequently, when these implications are incorpotated into the intiatives of security firms and government in promoting market participation, the perceptions and attitudes toward financial investment will be enhanced. These initiatives will facilitate low-cost financing for firm, thereby leading to sustainable development.

\section{CONCLUSION}

Psychology factors always exist in individuals naturally and can affect investors' behaviors. Studies on psychological factors help financial professionals as well as investors control these complex factors, which is contributed by the conduct of this research. The present study's results have proved the common existence of behavioral factors, namely personality traits and cognitive reflection, and their influences on risk aversion, thereby altering investment intentions and decisions. The research questions stated at the beginning of this paper could be answered as follows:

(i) Neuroticism, extraversion, and conscientiousness exert significant direct relationships, while agreeableness and openness to experience exert significant inverse relationships on risk aversion.

(ii) Performance in the Cognitive Reflection Test does provide evidence on people's risk preferences, the relationship of which is non-linear.

(iii) Risk aversion inversely influences short and long-term investment decision.

The analysis presented in this paper follows a new path to research agenda in Vietnam - behavioral finance. The 
conclusion from this study may have some limitations and not be of universal application because it was administered inside the Vietnamese border, with the respondents collected with convenience sampling. Additional empirical versification in more varied geographic areas and contexts using stratified or cluster random sampling would extend the application of the research. This study could only be, and was presented and analyzed in a realistic way based on the collected data.

Future researchers may address developed analyses regarding the impacts of the combination of the Big Five personality traits and cognitive reflection on other financial decision-making, such as emotional and cognitive biases. Future studies could also use more sophisticated empirical methods to quantify and analyze investors' personal characteristics to get more detailed results that can effectively help investors choose the appropriate investment strategy.

Thaler (1981, p. 198) states, "rational models tend to be simple and elegant with precise predictions, while behavioral models tend to be complicated, and messy, with much vaguer predictions". This study did not have the goal of developing a formal behavioral saving model, but only to accumulate empirical evidence that may be used to construct relationships among factors.

\section{ACKNOWLEDGMENTS}

This paper would not have been feasible without the invaluable assistance of several individuals. We would like to use this opportunity to express our heartfelt appreciation for their encouragement, understanding, and support. The authors gratefully acknowledge the contribution of the financial advisors and experts we have reached out to during the course of conducting the research for invaluable suggestions on the questionnaire as well as the general reasoning of this paper. This has helped a lot in improving the quality and mutual understanding between readers and author of the study. Besides, we are thankful for our acquaintances for their help to distribute questionnaires, and the respondents who participated in the survey.

\section{REFERENCES}

[1] Bortoli, D.D. et al. (2019) 'Personality traits and investor profile analysis: A behavioral finance study', PLOS ONE, 14(3), p. e0214062. doi:10.1371/journal.pone.0214062.

[2] Christelis, D., Jappelli, T. and Padula, M. (2010) 'Cognitive abilities and portfolio choice', European Economic Review, 54(1), pp. 18-38. doi:10.1016/j.euroecorev.2009.04.001.

[3] DeYoung, C.G., Grazioplene, R.G. and Peterson, J.B. (2012) 'From madness to genius: The
Openness/Intellect trait domain as a paradoxical simplex', Journal of Research in Personality, 46(1), pp. 63-78. doi:10.1016/j.jrp.2011.12.003.

[4] Dohmen, T. et al. (2018) 'On the Relationship between Cognitive Ability and Risk Preference', Journal of Economic Perspectives, 32(2), pp. 115134. doi:10.1257/jep.32.2.115.

[5] Durand, R.B., Newby, R. and Sanghani, J. (2008) 'An Intimate Portrait of the Individual Investor', Journal of Behavioral Finance, 9(4), pp. 193-208. doi:10.1080/15427560802341020.

[6] F. Hair Jr, J. et al. (2014) 'Partial least squares structural equation modeling (PLS-SEM): An emerging tool in business research', European Business Review, 26(2), pp. 106-121. doi:10.1108/EBR-10-2013-0128.

[7] Filbeck, G., Hatfield, P. and Horvath, P. (2005) 'Risk Aversion and Personality Type', Journal of Behavioral Finance, 6(4), pp. 170-180. doi:10.1207/s15427579jpfm0604_1.

[8] Frederick, S. (2005) 'Cognitive Reflection and Decision Making', Journal of Economic Perspectives, 19(4), pp. 25-42. doi:10.1257/089533005775196732.

[9] Kahneman, D. and Tversky, A. (1979) 'Prospect Theory: An Analysis of Decision under Risk', in Econometrica. The Econometric Society, pp. 263 292. Available at: https://doi.org/10.2307/1914185 (Accessed: 29 May 2021).

[10]Nandan, T. and Saurabh, K. (2016) 'Big-five personality traits, financial risk attitude and investment intentions: study on Generation ' $\mathrm{Y}^{\prime}$, International Journal of Business Forecasting and Marketing Intelligence, 2(2), pp. 128-150. doi:10.1504/IJBFMI.2016.078154.

[11] Nga, J.K.H. and Ken Yien, L. (2013) 'The influence of personality trait and demographics on financial decision making among Generation Y', Young Consumers, 14(3), pp. 230-243. doi:10.1108/YC-11-2012-00325.

[12] Nguyen H.T. (2020) 'Personality characteristics influencing stock investment intention through risk perception, uncertainty perception, and investment performance evaluation.', Journal of Commercial Science, 145, p. 11.

[13] Olsen, R.A. (2007) 'Investors' Predisposition for Annuities: A Psychological Perspective.', Journal of Financial Service Professionals, 61(5), pp. 5157. 
[14] Olsen, R.A. (2008) 'Cognitive Dissonance: The Problem Facing Behavioral Finance', Journal of Behavioral Finance, 9(1), pp. 1-4. doi:10.1080/15427560801896552.

[15] Park, N.Y. (2016) 'Domain-specific risk preference and cognitive ability', Economics Letters, 141, pp. 1-4. doi:10.1016/j.econlet.2016.01.008.

[16] Phares, E.J. (1988) Introduction to personality, 2nd ed. Glenview, IL, US: Scott, Foresman \& Co (Introduction to personality), pp. xxiv, 656.

[17] Pompian, M.M. (2016) Risk Profiling through a Behavioral Finance Lens, CFA Institute. Available at:

/en/research/foundation/2016/risk-profiling-through -a-behavioral-finance-lens (Accessed: 28 April 2021).

[18] Ricciardi, V. and Simon, H.K. (2001) What is Behavioral Finance? SSRN Scholarly Paper ID 256754. Rochester, NY: Social Science Research Network. Available at: https://papers.ssrn.com/abstract=256754 (Accessed: 17 April 2021).

[19] Saunders, M., Lewis, P. and Thornhill, A. (2019) Research methods for business students, 8th ed. Pearson. Available at: http://dspace.uniten.edu.my/jspui/handle/12345678 9/18304 (Accessed: 24 May 2021).

[20] Spaniol, J. and Bayen, U.J. (2005) 'Aging and Conditional Probability Judgments: A Global Matching Approach', Psychology and Aging, 20(1), pp. 165-181. doi:10.1037/0882-7974.20.1.165.

[21] Thaler, R.H. and Shefrin, H.M. (1981) 'An Economic Theory of Self-Control', Journal of Political Economy, 89(2), pp. 392-406. doi:10.1086/260971.

[22] Tran H. et al. (2020) 'The impact of personality traits on personal financial investment intentions: A study on Generation Y', Economics and Business Administration, 15(3), pp. 114-126. doi:10.46223/HCMCOUJS.econ.vi.15.3.1331.2020. 